erature on this subject, which so obviously persists in many branches of medicine even today? Should they be studying the placebo effect more closely so as to determine how to use it to aid their practice, instead of writing it off as an unwanted artefact?

The evaluation report concluded that we had identified areas central to the art of good doctoring, which seem not to be addressed directly by the mainstream medical curriculum for undergraduates. Such a conclusion is concerning; as Owen states, "How will those who choose not to do [the module] compensate for the lost opportunities of education?" The core medical curriculum at Glasgow has already changed in response to this dilemma. Based on the conclusions of the evaluation report, the undergraduate teaching from Glasgow's department of general practice now encourages more personal reflection and focuses more directly on the consultation, including those factors that influence its outcome.

Many challenges still exist, both for our own attitudes as students and for the undergraduate medical curriculum. We must focus on the bigger picture-producing student doctors who are aware of the value of having an appreciation of the art involved in medicine as well as the science, and of the importance of being a human being as well as a doctor.

Competing interests: None declared.

\title{
Regulation in complementary and alternative medicine
}

\section{Simon Y Mills}

Complementary Health Studies Programme Department of Lifelong Learning, School of Education, Exeter EX1 2LU Simon Y Mills research coordinator

S.Y.Mills@exeter. ac.uk

BMJ 2001;322:158-60
Complementary and alternative therapies have become more widely used over the past two decades, but many practitioners in the United Kingdom are largely unregulated. One of the recommendations of last year's report on complementary and alternative medicine by the House of Lords Select Committee on Science and Technology was that "in order to protect the public, professions with more than one regulatory body make a concerted effort to bring their various bodies together and to develop a clear professional structure." ${ }^{\prime}$ That some health professions remain unregulated in a developed country seems extraordinary, and I shall review how this situation has arisen before considering the prospects for change.

In the United Kingdom the common law right to choose one's own treatment for illness has been barely constrained by law. ${ }^{2}$ It is thus legal for practitioners to set themselves up in a wide variety of healthcare professions, as long as they do not claim to be registered medical practitioners and do not practise protected disciplines such as dentistry, midwifery, and veterinary medicine or supply medicines limited to prescription. By contrast, in most other European Union countries, as well as the United States, there are few healthcare activities that are allowed without state authorisation. Acupuncturists, herbalists, osteopaths, and naturopaths have been prosecuted for practising without medical qualifications, and the technical illegality of much complementary practice has meant that it has been pursued informally and disparately, with less opportunity for professional organisations to develop. The increasing demand for alternative health care across the developed world has, therefore, sometimes been met by practitioners outside the law and without recognisable training qualifications, professional standards, or insurance.

In the United Kingdom, the lack of proscription has meant that there are few formal obligations to meet any particular standard, and individual practitioners have been able to pursue their own path, even set up their own training programme or professional body, without sanction. They do not have to submit to authority, building their base on their ability to please

\section{Summary points}

Practitioners of complementary and alternative medicine in the United Kingdom are free to practice as they wish

Most therapies have set up professional bodies, but the educational standards required by these bodies vary widely

The House of Lords recently reviewed complementary and alternative medicine and recommended clearer regulation

Because of the wide variation in therapies, each discipline should initially set up its own regulatory body, although it may be possible to combine these later

Many patients consult complementary practitioners without telling their doctor, with possible detrimental effects on health care; greater cooperation and respect between orthodox and complementary practitioners would improve communication with patients

their market-their patients. On the other hand, a benign legal climate has also allowed enlightened responses to increasing public demand. The natural instinct for self enhancement of professional status has led most practitioners to subscribe to organisations overtly raising standards. In 1997 and 2000 the Centre for Complementary Health Studies reported the results of surveys of about 140 professional bodies representing about 50000 practitioners working in up to 30 complementary or alternative therapies. ${ }^{34}$ Professional standards varied widely. In part to reflect this diversity, the House of Lords report classified complementary and alternative therapies into three groups (box) and related many of its recommendations to this classification. 
Two disciplines, osteopathy and chiropractic, have moved along the path of self regulation and now have acts of parliament that protect their titles and provide additional external and orthodox regulation of their activities. Both the General Osteopathic Council and the General Chiropractic Council have opened their statutory registers. Once the process of registering existing practitioners is complete, it will be a criminal offence to practice as an osteopath or chiropractor unless you are registered with the appropriate council.

The House of Lords also identified acupuncture and herbal medicine as two therapies ready for moves towards statutory regulation under the Health Act 1999 and considered such moves might later be appropriate for non-medical homoeopaths.

\section{Codes of professional conduct and public accountability}

Most complementary medicine organisations are run as conventional professional bodies; they publish formal codes of ethics and practice, and registers of their members are available to the public. Almost all subscribe to insurance schemes that provide professional indemnity and public liability cover for their members (the cost of cover is generally not high, reflecting the lack of litigation so far in this area). However, the opportunity for the public to pursue complaints against practitioners, and the provision of

\section{Categories of complementary and alternative therapies $^{1}$}

Group 1: Professionally organised alternative therapies

Acupuncture

Chiropractic

Herbal medicine

Homoeopathy

Osteopathy

Group 2: Complementary therapies

Alexander technique

Aromatherapy

Bach and other flower extracts

Body work therapies, including massage

Counselling stress therapy

Hypnotherapy

Meditation

Reflexology

Shiatsu

Healing

Maharishi Ayurvedic medicine

Nutritional medicine

Yoga

Group 3: Alternative disciplines

3a:Long established and traditional systems of healthcare

Anthroposophical medicine

Ayurvedic medicine

Chinese herbal medicine

Eastern medicine (Tibb)

Naturopathy

Traditional Chinese medicine

3b: Other alternative disciplines

Crystal therapy

Dowsing

Iridology

Kinesiology

Radionics

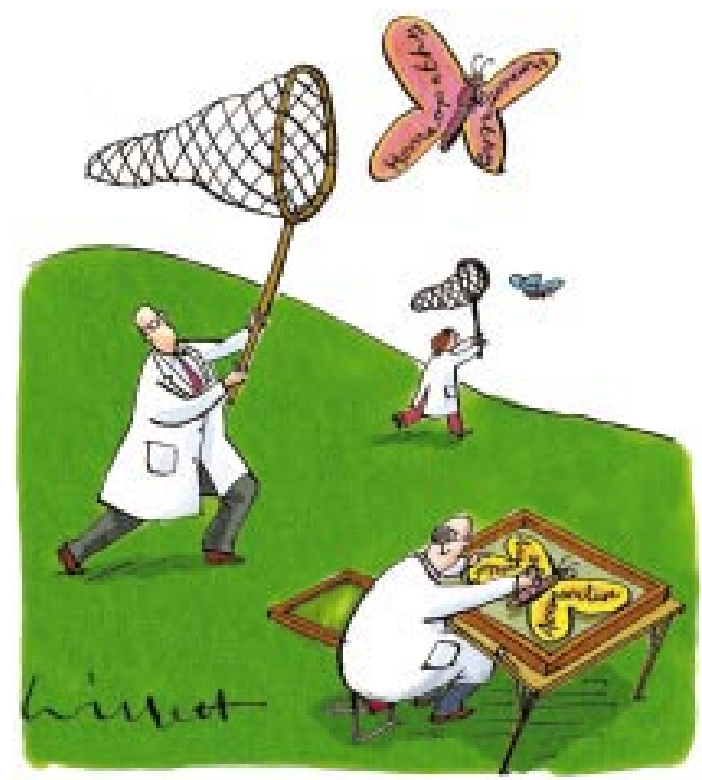

formal disciplinary codes, sanctions, and procedures and published complaint procedures was notably patchy, even among well established organisations. Given the moves to increase professional accountability in the medical profession, complementary and alternative medicine organisations will need to increase public scrutiny of their affairs, regardless of whether they get statutory regulation.

\section{Educational standards}

Little external pressure has been put on practitioners of complementary and alternative medicine to reach any particular educational standard. Those professional organisations that have attempted to raise standards have been self motivated. The House of Lords report, however, recommended that regulatory bodies set objectives of training and define core competencies. Such objectives will clearly depend on the extent to which a profession claims that its members see patients independently of the family doctor. The Centre for Complementary Health Studies found that most practitioners of complementary or alternative medicine were likely to do so. ${ }^{34}$ On the other hand, much anecdotal evidence, supported by at least one systematic study, ${ }^{5}$ has suggested that most patients consult complementary practitioners concurrently with conventional medical doctors.

Practitioners of many therapies-for example, those classified as complementary therapies in the box-are unlikely to tackle critical diagnostic issues or face the prospect of serious interaction with medical treatment. Nevertheless, other therapists may see patients who choose not to consult a doctor, and some practitioners may even encourage such independence. This uncertainty needs to be clarified: if complementary and alternative medical professions claim therapeutic autonomy then they are vulnerable to the charge that only a full medical education can equip them to work independently of doctors. ${ }^{6}$

It could also be argued that all practitioners of complementary or alternative medicine should show that they are aware of potentially dangerous situations and know the contraindications for their practice, 
possible adverse effects, and mechanisms of referral to medical treatment. ${ }^{7}$ As complementary medicine grows the public may become more careful of its claims. The current position whereby organisations can happily operate at almost any level they want may not be tenable. Organisations should develop realistic strategies to justify how they would handle patients who have not already been assessed by a doctor. Such progress is most likely through more rigorous educational curriculums-for example, imbuing the new generation of practitioners with the necessary culture of inquiry. This will lead to better articulation of limits to practice (and efficacy) and encourage fruitful debate with other health professionals.

Progress has been made. Leading groups of complementary and alternative practitioners have established degree courses at, or validated by, universities (this is particularly notable among therapies in group 1 ). Other professional groups are considering the precedent set by the British Acupuncture Accreditation Board. The board, which has an independent chair and a majority of non-acupuncturists, was established by leading acupuncture professional organisations and colleges as a forum to assure the public that subscribing colleges are meeting self imposed criteria for educational achievement and to formally engage the public in the overall debate. ${ }^{8}$

\section{Role of organisations representing other health practitioners}

The position of organisations which represent doctors, nurses, midwives, physiotherapists, chiropodists, and other registered health professionals who practise complementary therapies is bound to be different from that of organisations principally concerned with representing complementary specialists. There may, for example, be a view that what is being practised is a "technique" rather than a wider encompassing "therapy," with the corresponding assumption that training standards need not be particularly rigorous. However, the House of Lords report took a firm view on the standards that such bodies need to apply: "We recommend that if CAM [complementary and alternative medicine] is to be practised by any conventional healthcare practitioners, they [patients] should be treated to standards comparable to those set out for that particular therapy by the appropriate (single) CAM regulatory body."

\section{Prospects for professional integration}

The surveys by the Centre for Complementary Health Studies confirmed that there is no immediate prospect of a concerted move for wholesale integration of complementary and alternative medicine with the wider medical community. ${ }^{3}$ In both accomplishment and aspiration, the groups are too disparate to be considered as one movement. Indeed it is misleading to view them as such.

In the 1980s, as complementary therapies became more widely used, many practitioners pressed for the development of complementary medicine as a whole. It soon became clear, however, that it would be more feasible for the various professions to develop at different paces, to reflect the variety of their characteristics and aspirations. Nevertheless, because many practitioners use more than one therapy it may be too complicated and expensive for individual practitioners to belong to separate registers for each therapy. This leads to the argument that legislation should be essentially unitary, with something resembling a Council of Professions Complementary to Medicine.

The Lords report concluded that the best prospects for coordination are likely to come from each discipline setting its own standards and competence. There is an obvious benefit for the public as well as the practitioner in agreeing what a particular therapy actually entails. The final, and most appropriate, shape of any statutory regulation could then emerge more clearly once individual standards have been set.

In 1997 the Foundation for Integrated Medicine published a discussion document on the way forward for integrated medicine after wide consultation across conventional and complementary medicine. ${ }^{9}$ The document set out the work of four expert working groups on research and development, education and training, delivery mechanisms, and regulation. It also made important recommendations for regulation of complementary medicine, including criteria for any system of self regulation. The foundation has encouraged integration among complementary medicine professions and has recently received a grant from the King's Fund to help it to work towards forming central regulatory bodies.

\section{Conclusions}

Public demand for complementary medicine has grown to a level where communication and cooperation with orthodox health services is necessary. ${ }^{10}$ Many patients see complementary practitioners concurrently with their doctor. However, they often do not tell their doctor about it, perhaps because they fear a negative response. Evidence that professionals from all parts of the healthcare spectrum were engaging in constructive debate about their relative roles would encourage greater communication between all practitioners and their patients.

Competing interests: SYM is a former director of the Centre for Complementary Health Studies and was a specialist advisor to the House of Lords Select Committee on Science and Technology report on complementary and alternative medicine. He is co-chair of the regulatory working group of the Foundation for Integrated Medicine.

1 House of Lords Select Committee on Science and Technology Complementary and alternative medicine: session 1999-2000, 6th report. London: Stationery Office, 2000

2 Stone J, Matthews J. Complementary medicine and the law. Oxford: Oxford University Press, 1996.

3 Mills S, Peacock W. Professional organisation of complementary and alternative medicine in the United Kingdom 1997: a report to the Department of Health. Exeter: Centre for Complementary Health Studies, University of Exeter, 1997.

4 Mills S, Budd S. Professional organisation of complementary and alternative medicine in the United Kingdom 2000: a second report to the Department of Health. Exeter: Centre for Complementary Health Studies, University of Exeter, 2000.

5 Thomas K, Carr J, Westlake L, Williams BT. Use of non-orthodox and conventional health care in Great Britain. BMJ 1991;302:207-10.

6 Ernst E. Competence in complementary medicine. Complementary Therapies in Medicine 1995:3:6-8.

7 Mills S. Safety awareness in complementary medicine. Complementary Therapies in Medicine 1996;4:48-51.

8 Shifrin K. Setting standards for acupuncture training-a model for complementary medicine. Complementary Therapies in Medicine 1993;1:91-5.

9 Foundation for Integrated Medicine. Integrated healthcare: a way forward for the next five years? London: FIM, 1998.

10 Dickinson DPS. Complementary therapies in medicine: the patient's perspective. Complementary Therapies in Medicine 1995;3:9-12. 